\title{
Management of Cough in Patients with Chronic Obstructive Pulmonary Disease: Results of the Multicenter Randomized Placebo-Controlled Clinical Trial
}

Sergey N Avdeev, (D) 'Alexander A Vizel, ${ }^{2}$ Vladimir N Abrosimov, ${ }^{3, \dagger}$ Andrey A Zaicev, ${ }^{4}$ Galina L Ignatova, ${ }^{5}$ Rustem F Khamitov, ${ }^{2}$ Marina P Mikhaylusova, ${ }^{6}$ Julia S Shapovalova, ${ }^{7}$ Elena F Pavlysh, ${ }^{8}$ Basil I Trofimov, ${ }^{9}$ Alexander V Emelyanov, ${ }^{10}$ Tatiana I Martynenko, (D) 11 Vladimir A Martynenko, ${ }^{2}$ Natalia E Kostina, ${ }^{13}$ Danila A Chizhov, ${ }^{14}$ Olga Yu Chizhova, ${ }^{10}$ Natalia A Kuzubova, ${ }^{15}$ Elena $\vee$ Makova, (iD) ${ }^{16}$ Ekaterina $\vee$ Makarova (D) ${ }^{17,18}$

II.M. Sechenov First Moscow State Medical University, Moscow, Russia; ${ }^{2}$ Kazan State Medical University, Kazan, Russia; ${ }^{3}$ Ryazan State Medical University Named After Academician I.

P. Pavlov, Ryazan, Russia; ${ }^{4}$ The Main Military

Clinical Hospital Named After Academician N. N. Burdenko, Moscow, Russia; ${ }^{5}$ Regional

Clinical Hospital No. 4, Chelyabinsk, Russia;

${ }^{6}$ Pirogov Russian National Research Medical

University, Moscow, Russia; ${ }^{7}$ Chelyabinsk Road

Clinical Hospital "Russian Railways",

Chelyabinsk, Russia; ${ }^{8}$ Nikiforov's All-Russian

Center for Emergency and Radiation Medicine

of the Emergencies, St. Petersburg, Russia; ' 1. P.

Pavlov First Saint Petersburg State Medical

University, St. Petersburg, Russia; ${ }^{10}$ North-

Western State Medical University Named After

I.I. Mechnikov, St. Petersburg, Russia;

"Regional State City Hospital No. 5, Barnaul,

Russia; ' 2 Regional State Clinical Hospital,

Barnaul, Russia; ${ }^{13}$ Voronezh Regional Clinical

Hospital No. I, Voronezh, Russia;

${ }^{14}$ St. Petersburg State City Polyclinic No. 106,

St. Petersburg, Russia; ${ }^{15}$ St. Petersburg State

$\checkmark v e d e n s k a y a$ City Clinical Hospital,

St. Petersburg, Russia; ${ }^{16}$ State Samara City

Hospital No. 4, Samara, Russia; ${ }^{17}$ Privolzhsky

Research Medical University, Nizhny

Novgorod, Russia; ${ }^{18}$ State City Clinical Hospital

No. 10, Nizhny Novgorod, Russia

†Professor Vladimir Abrosimov passed away on January 22, 2019

Correspondence: Sergey N Avdeev I.M. Sechenov First Moscow State Medical University, 8-2, Trubetskaya St., Moscow,

I I999I, Russia

Tel +7-495-465-74- 15

Fax +7-495-465-52-64

Email serg avdeev@list.ru
Background: Chronic cough declines quality of life and increases risk of complications in patients with chronic obstructive pulmonary disease (COPD). Reducing cough severity and associated negative effects is important therapeutic goal in COPD. Rengalin with anti- and protussive activity is based on technologically processed antibodies to bradykinin, histamine and morphine.

Aim: To evaluate efficacy and safety of Rengalin in treatment of cough in patients with COPD. Methods: Patients ( $n=238$, mean age $64.3 \pm 8.2$ years) with stable COPD and persistent cough despite maintenance therapy (anticholinergics, beta-2-adrenergic agonists, inhaled corticosteroids) were included and randomized in the study. The severity of cough assessment (according to the "Cough Severity Score"), COPD impact on patient's life (COPD Assessment Test, CAT), and spirometry were performed at screening. Patients took Rengalin or Placebo 2 tablets 2 times daily for 4 weeks. The endpoints were proportion of patients who responded to treatment, dynamics of cough severity, and severity of COPD symptoms. Intention-to-treat (per protocol) analysis was performed.

Results: Positive response to Rengalin was recorded in 83.6 [85.7]\% (vs 72.6 [72.7]\% in Placebo group, $\mathrm{p}=0.0422$ [ $\mathrm{p}=0.0163]$ ). Double decrease of cough severity was reported in 42.2 [43.8]\% in Rengalin group (versus 32.7 [32.7]\% in Placebo; $p=0.1373$ [ $p=0.0907]$ ). The total CAT score decreased by $3.3 \pm 4.2$ [3.6 \pm 3.9$]$ points (versus $2.5 \pm 4.1[2.5 \pm 4.2]$ in Placebo group); the difference between groups was $0.79 \pm 4.16$ [1.04 \pm 4.02$]$ points ( $p=0.0870$ $[p=0.0416])$. The number of patients with adverse events (AEs) in Rengalin ( $n=13)$ and Placebo $(n=12)$ groups did not have significant differences $(p=1.00)$. No AEs with certain relationship with study drug were registered.

Conclusion: Rengalin is an effective and safe drug in patients with stable COPD and persistent cough, despite stable doses of maintenance therapy according to the GOLD guidelines. Fourweek therapy decreases severity of cough by two times in more than $40 \%$ of patients.

Trial Registration: ClinicalTrials.gov (id: NCT03159091).

Keywords: cough, cough management, chronic obstructive pulmonary disease, treatment, Rengalin

\section{Introduction}

Chronic obstructive pulmonary disease (COPD) is a common, preventable, and treatable disease characterized by an irreversible or partially reversible obstruction of airways, primarily due to chronic inflammatory pulmonary response caused by 
the effect of noxious particles or gases. ${ }^{1,2}$ COPD is a progressive disease, which leads to worsening of patient's quality of life (QoL): decreased tolerance of physical activity, limitations in everyday life, increased cough, shortness of breath, and sleep disturbances. ${ }^{3}$ The prevalence rate of this disease in the world at the end of 2019 was 384 million cases. COPD causes the deaths of 3 million people annually. ${ }^{4}$ According to the study conducted by Wacker et al (2017), average annual per patient costs for COPD treatment in Europe were $7263 €$. The high comorbidity of COPD increases the risk of severe complications, worsens the prognosis, and raises the cost of treatment. ${ }^{5}$

The main symptoms of COPD include shortness of breath, cough, sputum production, wheezing, and chest tightness. The prevalence of symptoms varies depending on patient population and disease severity. ${ }^{6}$ Chronic cough is frequently the first symptom of COPD, and it is underestimated by patients and considered to be an expected consequence of smoking and/or an environmental effect. Apart from maintenance therapy, which is aimed at achieving COPD control, concomitant treatment is important, and it is directed to improve patient's QoL, including through the treatment of cough. With COPD, as with other chronic respiratory diseases, it is crucial to manage the cough. Cough management involves the rational use of drugs blocking the cough reflex and/or optimizing the sputum removing. ${ }^{7}$

Recently, it was revealed that high dilutions of any substance obtained using a technological process, namely by a repeated dilution of the original substance in combination with an external physical impact, have an ability to modify the activity of the original substance. ${ }^{8}$ High dilutions should be considered as a product of technological processing of the original substance rather than its small dose. It has been established that the trigger mechanism of action of high dilutions is their ability to exert changes on conformation of the original substance/target molecule. ${ }^{9}$

The efficacy and safety of the high dilutions have been clinically proven in numerous studies conducted in accordance with the evidence-based medicine. ${ }^{10-12}$

Rengalin for cough treatment (OOO NPF MATERIA MEDICA HOLDING) with anti- and protussive activity is manufactured on the base of technologically processed antibodies to bradykinin (anti-B), histamine (anti-H) and morphine (anti-M). The active components of Rengalin modify the ligand-receptor interaction of bradykinin, histamine, and endogenous opioids with their receptors. ${ }^{13}$
According to in vivo studies, anti-B reduces the number of cough episodes caused by capsaicin and citric acid. Anti-H modulates the activity of $\mathrm{H} 1, \mathrm{H} 2$ and $\mathrm{H} 3$ receptors, reduces peripheral vascular permeability, bronchial smooth muscle spasm, mucus production, and histamine liberation. Anti-M targets are coughing reflex centers. Due to the complex influence of all components, Rengalin affects the central and peripheral pathways, regulates cough, and also decreases the swelling and exudative inflammation, which provides a broncholytic effect, and relieves a sputum expectoration. ${ }^{13}$

This article presents the results of the clinical trial performed to evaluate the efficacy and safety of Rengalin for treatment of cough in patients with stable course of COPD.

\section{Materials and Methods Study Design}

The study was a multicenter, double-blind, placebo-controlled, randomized clinical trial and was conducted in 18 clinical sites performing outpatient care located in various cities of the Russian Federation, including Moscow, Saint Petersburg, Ryazan, Kazan, Chelyabinsk, Barnaul, Voronezh, Samara, etc. Study duration was 32 months (from June 2017 to April 2019). The study was conducted in accordance with the principles of the Declaration of Helsinki and Good Clinical Practice. It was permitted by the Ministry of Health of the Russian Federation. The study was approved by the institutional review boards and the National Council for ethics. Signed informed consent was obtained from all participants prior to enrollment.

At the screening stage (Visit 1), cough severity was evaluated according to the "Cough symptom score" $(\mathrm{CSS})^{7,14}$ assessing the number of episodes and cough severity during the last 24 hours, and the impact of COPD on a person's life was measured (COPD Assessment Test, CAT). Computer-based spirometry was performed to assess forced expiration volume in 1 second $\left(\mathrm{FEV}_{1}\right)$, forced vital capacity (FVC), and the $\mathrm{FEV}_{1} / \mathrm{FVC}$ index. A bronchial dilation test was also performed and post bronchial dilation $\mathrm{FEV}_{1}$ was determined.

At the end of the screening and upon inclusion in the study at Visit 1 (Day 1), the patients were randomized in two groups using an automatic interactive voice/web response randomization system that generated random numbers in a 1:1 ratio. Group 1 patients took 2 tablets of Rengalin twice daily for 4 weeks, group 2 patients took 2 
tablets of Placebo twice daily for 4 weeks. In order to maintain confidentiality, each patient was assigned a personal code, which did not change during the study. This study used a double-blind placebo control. The Rengalin and Placebo tablets looked the same and had similar organoleptic properties. The study drug was provided in boxes and packages without information identifying the active ingredient. Participants, investigators, staff at the study sites, and the sponsor team for this project were not informed of the assigned study therapy (Rengalin or Placebo) prior to the study's completion and closure of the database.

Patients were provided with diary card in which they recorded the time of the usage and dose of the study drug, marked the daytime and night-time cough severity in the table according to CSS, wrote the name and dose of medications for maintenance therapy of COPD.

Each patient was under observation for 4 weeks. At Visit 2 (Week 4) patients were re-evaluated for cough severity (CSS) and the impact of COPD on their life (CAT).

Vital functions were assessed at the outset and at the end of treatment. During the study, the presence and type of adverse events (AEs), their intensity (degree of severity), the relation to the study drug, and outcomes were evaluated.

\section{Inclusion Criteria}

The study included outpatients from 40 to 80 years of age, with COPD diagnosed more than 12 months ago (according to the Global Initiative for Chronic Obstructive Lung Disease (GOLD) guidelines 2016), a stable course of COPD (lack of disease progression during $\geq 6$ months), a mild/moderate/severe degree of bronchial obstruction $\left(\mathrm{FEV}_{1} / \mathrm{FVC}<0.7\right.$; post bronchial dilation $\mathrm{FEV}_{1} \geq 30 \%$ of required), cough severity $\geq 2$ points (according to CSS), and stable doses of maintenance therapy during the previous 4 weeks. Contraceptive use by the patients of reproductive age of both sexes during the study and 30 days after its completion was a requirement.

The study did not include patients with previously diagnosed intra- and extrathoracic causes of cough (eg, asthma, malignant neoplasm of lung, tuberculosis, sarcoidosis, $\alpha 1$-antitrypsin deficiency, bronchiectasis, cystic fibrosis, interstitial lung diseases, perennial allergic rhinitis, gastroesophageal reflux disease, use of ACE inhibitors, disease of upper respiratory tract, etc.), COPD exacerbation, acute respiratory infection of upper and/or lower airways, cough due to food intake, very severe airflow limitation, changes of the maintenance therapy (within the previous 4 weeks), hemoptysis, history of stroke (within the previous 3 months), acute cardiovascular or neurological diseases (within the previous 36 or 3 months, respectively), oncological disease, mental illness, chronic kidney disease (class C3-5 A3), liver failure (C class according to Child-Pugh), with a body mass index $\leq 18 \mathrm{~kg} / \mathrm{m}^{2}$ or $\geq 40 \mathrm{~kg} / \mathrm{m}^{2}$. Patients with an expected smoking cessation over the next 4 weeks (for smokers) or with intolerance of any of the components of the drugs used in the study or using recreational drugs were not included.

In the course of treatment, the patients received the maintenance COPD treatment including anticholinergic drugs, $\beta_{2}$-agonists, inhaled corticosteroids (ICS), methylxanthines and their combinations. Four weeks prior to inclusion in the study and also during the study the following drugs were prohibited for use: expectorants, mucolytics, cough suppressants and their combined products, fenspiride, icatibant, antihistamines for systemic use, cold preparations, angiotensin-converting enzyme inhibitors and their combinations, glucocorticoids for systemic use, centrally acting muscle relaxants, antibacterials for systemic use, and drugs with an irritating or suppressing effect on the cough center (including as a side effect).

\section{Description of Medical Intervention}

Rengalin or placebo were prescribed as 2 tablets twice daily (15-30 minutes before a meal or 15-30 minutes after a meal) for 4 weeks. Patient compliance with the study drug was determined by calculating the prescribed tablets returned at the final visit, according to the formula $\mathrm{N}=\left(\mathrm{Q}_{\text {issued }}-\mathrm{Q}_{\text {returned }}\right) / \mathrm{Q}_{\text {required }} \times 100 \%$, where $\mathrm{N}$ is the assessed level of treatment compliance, $\mathrm{Q}_{\text {issued }}$ is the number of tablets issued to the patient, $Q_{\text {returned }}$ is the number of tablets returned by the patient, and $\mathrm{Q}_{\text {required }}$ is the number of tablets the patient was required to take during the whole treatment period according to the treatment regimen.

The primary efficacy endpoint was the percentage of patients who responded to treatment in 4 weeks. Response criterion was a decrease in the total score according to the CSS scale by $\geq 1$ point compared to the baseline.

The secondary endpoints were the dynamics of cough severity, the percentage of patients with decreased cough severity by $50 \%$ after 4 weeks of treatment, the change of severity of clinical signs of COPD (according to the CAT), 
and the percentage of patients without COPD exacerbation during 4 weeks of treatment.

\section{Assessment Methods and Treatment Outcomes}

To evaluate cough severity, a 6-point CSS scale was used ( 0 points - no cough, 5 points - severe cough). ${ }^{7,14}$ The initial and final total scores for cough severity were determined by a physician/pulmonologist on the base of the daytime and night-time cough scores within the previous 24 hours.

The impact of COPD on daily life was assessed using the CAT questionnaire. ${ }^{1} \mathrm{~A}$ total score $\leq 10$ indicates an insignificant impact, $11-20$ points - moderate, 21-30 points - strong, and 31- 40 - a very strong impact of COPD on the patient's life.

At the screening stage, computer-based spirometry was performed according to the common method with evaluation of the initial parameter $\mathrm{FEV}_{1} / \mathrm{FVC}$ and post bronchial dilation $\mathrm{FEV}_{1}$. The results of previously conducted studies over the last 3 months were also considered.

COPD exacerbation was defined as an acute event, characterized by a worsening of the condition (increased severity of respiratory complications beyond the daily normal fluctuations), for 2-3 days or more.

\section{Statistical Analysis}

Evaluation of sample size for efficacy analysis was performed assuming that the difference between the proportion of patients who responded to treatment in Rengalin group and Placebo group would be no less than 0.2 , in favor of Rengalin. The size of type I error would be no more than 0.05 , type II error - no more than 0.2 .

The minimum required size for each group was 95 patients. Thus, at least 238 patients had to be included in the study, taking into account the dropout rate set at $20 \%$.

Data analysis was performed using SAS 9.4 (SAS Institute Inc., Cary, NC). Fisher's exact test and G-test were used to compare the proportions in two groups. Student's $t$-test or Wilcoxon test was used for continuous variables, depending on the result of Shapiro-Wilks normality test; the longitudinal data in the two groups were analyzed with two-way analysis of variance for repeated measures (Repeated Measures ANOVA, PROC MIXED).

\section{Study Results}

Characteristics of Study Participants

A total of 238 patients were included in the study and randomized. Nine patients were excluded from the full analysis set (FAS) due to the following reasons: 8 patients were included mistakenly without meeting inclusion criteria or with meeting non-inclusion criteria ( $\mathrm{n}=5$ in Rengalin group; $\mathrm{n}=3$ in Placebo group), and 1 patient did not take a single dose of the study drug $(n=1$ in Placebo group). The rest of the participants $(n=229)$ constituted the intention-to-treat (ITT) analysis set, including 116 in Rengalin group and 113 in Placebo group. Safety analysis was performed in all randomized patients who received at least one dose of Rengalin $(n=121)$ or placebo $(n=116)$.

Seven patients were excluded from the Per Protocol (PP) analysis for various reasons. The population used for the PP analysis included 222 patients ( $\mathrm{n}=112$, in Rengalin group; $\mathrm{n}=110$ in Placebo group; PP analysis results are shown in square brackets). Patient flow diagram is shown in Figure 1.

The patients in two groups did not vary in demographic (Table 1) and baseline clinical characteristics (Table 2). Patients of both groups had a cough, which decreased their daily activity and/or disturbed their sleep at night. Initial cough severity was $4.2 \pm 1.4$ [4.2 \pm 1.4$]$ points in Rengalin group and $4.1 \pm 1.4[4.1 \pm 1.4]$ in Placebo group $(\mathrm{p}=0.82$ $[\mathrm{p}=0.10])$. Average value of the total score on the CAT questionnaire was $19.9 \pm 6.8$ [19.8 \pm 6.6$]$ in Rengalin group and $20.3 \pm 6.6[20.3 \pm 6.7]$ in Placebo group $(p=0.67$ $[p=0.61]$ ), which showed that COPD had a moderate/ strong impact on the daily life activities of patients in both groups.

Most patients (80.2 [83.0]\% of Rengalin group and 81.4 [82.7]\% of Placebo group) had a concomitant disorders, including arterial hypertension (64.7 [67.0]\% and $61.1[60.9] \%)$, heart diseases $(28.4[29.5] \%$ and 29.2 $[29.1] \%)$, muscular-skeletal system diseases (15.5 [16.1]\% and 18.6 [19.1]\%), endocrine diseases, nutrition and metabolism disorders $(15.5[16.1] \%$ and 11.5 [11.8]\%), gastrointestinal tract diseases (11.2 [11.6]\% and $15.9[16.4] \%)$, hepatobiliary system diseases $(6.0[6.3] \%$ and $7.1[6.4] \%)$, nervous system diseases (6.0 [6.3]\% and $14.2[14.4] \%)$, and ophthalmic diseases (7.8 $[8.0] \%$ and $7.1[7.3] \%)$.

The patients in both groups received the drugs for maintenance therapy: anticholinergics, beta-2 adrenergic 


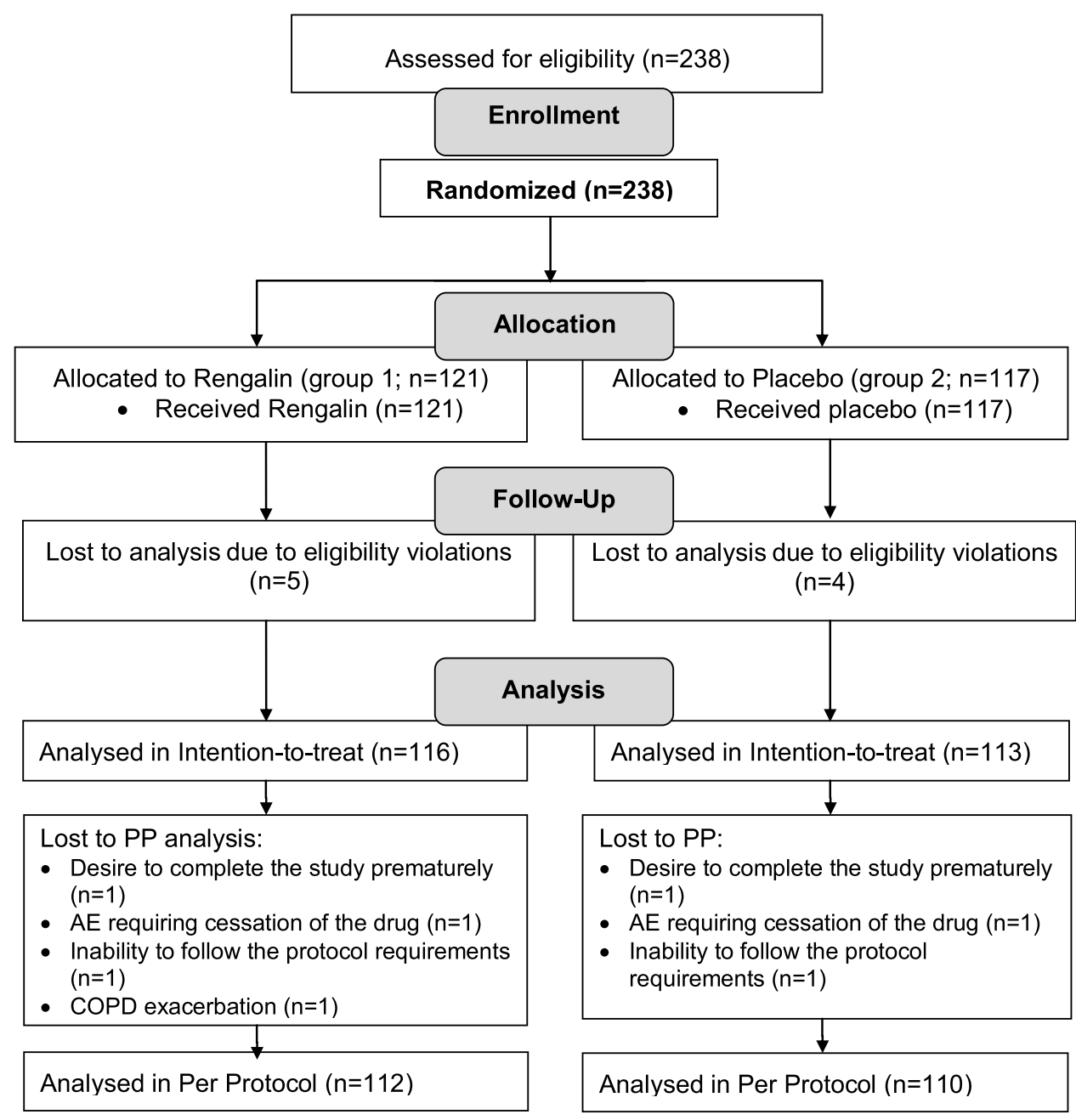

Figure I Flow diagram.

agonists, ICS and their combinations. Patients took drugs for treatment of concomitant diseases, including calcium channel blockers (30.2 [28.6]\% of Rengalin group patients and $31.0[30.0] \%$ of Placebo group patients), angiotensin receptor antagonists (19.8 [17.9]\% and 15.9 [15.5]\%), beta-adrenergic blockers (9.5 [9.8]\% and $7.1[6.4] \%)$, diuretics (6.9 [7.1]\% and $3.5[2.7] \%)$, imidazoline receptor agonists (3.4 [3.6]\% and 3.6 [3.6]\%), statins (14.7 [15.2]\% and $13.3[12.7] \%)$, antiaggregants (19.8 [17.9]\% and 19.5 $[16.4] \%)$, and oral hypoglycemic agents $(6.0[6.3] \%$ and $5.3[5.5] \%)$.

The groups did not differ in the number of comorbidities $(p=0.87[p=1.00])$ and the use of the drugs for concomitant treatment $(\mathrm{p}=1.00[\mathrm{p}=1.00])$.

The level of patient compliance to the prescribed treatment was $97.3 \pm 11.7[97.6 \pm 6.4] \%$ in Rengalin group and $97.7 \pm 12.0 \quad[98.5 \pm 7.9] \%$ in Placebo group $\quad(p=0.22$ $[\mathrm{p}=0.18])$.

\section{Results of the Study Efficacy Assessment}

The proportion of patients responsive to Rengalin treatment was 83.6 [85.7]\% (against 72.6 [72.7]\% in Placebo group) (Figure 2). The proportion of patients with clinically significant improvement in their cough was significantly higher in Rengalin group than in Placebo group $(p=0.0422[p=0.0163])$.

After 4 weeks of Rengalin treatment the total CAT score decreased by $3.3 \pm 4.2$ [3.6 \pm 3.9$]$ points (compared to $2.5 \pm 4.1$ [2.5 \pm 4.2$]$ in Placebo group) (Table 3, Figure 3). The difference (delta) between the groups was $0.79 \pm 4.16$ [1.04 \pm 4.02$]$ points, which according to the PP analysis was statistically significant $([\mathrm{p}=0.0416])$.

A decrease in cough severity by $50 \%$ or more after 4 weeks of treatment was observed in 42.2 [43.8]\% of Rengalin group patients (compared to 32.7 [32.7]\%) in Placebo group ( $\mathrm{p}=0.14$ $[\mathrm{p}=0.09])$. 
Table I Patient Demographic Characteristics

\begin{tabular}{|c|c|c|c|c|}
\hline \multirow[t]{2}{*}{ Parameter } & \multicolumn{2}{|c|}{ Group } & \multirow[t]{2}{*}{ Total } & \multirow[t]{2}{*}{ Statistics } \\
\hline & Rengalin & Placebo & & \\
\hline $\begin{array}{l}\text { All Included } \\
\text { Patients }\end{array}$ & $N=|2|$ & $N=1$ I 7 & $N=238$ & \\
\hline \multicolumn{5}{|l|}{ Age, years } \\
\hline Mean \pm SD & $63.9 \pm 7.9$ & $64.8 \pm 8.4$ & $64.3 \pm 8.2$ & $\mathrm{t}=0.86$ \\
\hline Median & 65 & 66 & 65 & $P=0.39$ \\
\hline Minimum & 44 & 45 & 44 & \\
\hline Maximum & 80 & 80 & 80 & \\
\hline QI-Q3 & $58-69$ & I9-7I & 58-7| & \\
\hline \multicolumn{5}{|l|}{ Gender, n (\%) } \\
\hline Male & 94 (77.7) & $94(80.3)$ & $188(79.0)$ & $p=0.64$ \\
\hline Female & $27(22.3)$ & $23(19.7)$ & $50(21.0)$ & \\
\hline ITT Analysis & $N=116$ & $N=113$ & $N=230$ & Statistics \\
\hline \multicolumn{5}{|l|}{ Age, years } \\
\hline Mean \pm SD & $63.7 \pm 8.0$ & $64.7 \pm 8.6$ & $64.2 \pm 8.3$ & $\mathrm{t}=0.92$ \\
\hline Median & 65 & 65 & 65 & $p=0.36$ \\
\hline Minimum & 44 & 45 & 44 & \\
\hline Maximum & 80 & 80 & 80 & \\
\hline QI-Q3 & $58-69$ & $58-7 \mid$ & $58-70$ & \\
\hline \multicolumn{5}{|l|}{ Gender, n (\%) } \\
\hline Male & $90(77.6)$ & 90 (79.7) & $180(78.6)$ & $\mathrm{P}=0.75$ \\
\hline Female & $26(22.4)$ & $23(20.3)$ & $49(2 I .4)$ & \\
\hline PP Analysis & $N=1 / 2$ & $N=110$ & $\mathrm{~N}=222$ & Statistics \\
\hline \multicolumn{5}{|l|}{ Age, years } \\
\hline Mean \pm SD & $63.8 \pm 8.1$ & $64.7 \pm 8.6$ & $64.2 \pm 8.4$ & $\mathrm{t}=0.88$ \\
\hline Median & 65 & 65 & 65 & $p=0.38$ \\
\hline Minimum & 44 & 45 & 44 & \\
\hline Maximum & 80 & 80 & 80 & \\
\hline QI-Q3 & $58-69$ & $58-7 \mid$ & $58-70$ & \\
\hline \multicolumn{5}{|l|}{ Gender, n (\%) } \\
\hline Male & $86(76.8)$ & 87 (79.1) & 174 (77.9) & $\mathrm{P}=0.75$ \\
\hline Female & $26(23.2)$ & $23(20.9)$ & $49(22.1)$ & \\
\hline
\end{tabular}

Notes: Mean $\pm S D$ - mean value and its standard deviation. Patients age was analyzed with Stuart's t-criterion; the result of the null test with Shapiro-Wilk criterion: Rengalin $-p=0.2813$, Placebo $-p=0.0740$. Comparison of the groups according to set was performed with the Fisher criterion.

Neither group differed in the number of patients without COPD exacerbation $(\mathrm{p}=1.00[\mathrm{p}=1.00])$.

\section{Safety Assessment}

In total, during treatment and observation 16 AEs were registered in $13(10.7 \%)$ Rengalin group patients and 12 AEs were registered in 12 (10.3\%) Placebo group participants. Frequency analysis using Fisher's exact test did not show statistically significant differences between the number of patients with AEs in two groups $(\mathrm{p}=1.000)$.

Gastrointestinal symptoms (nausea, $\mathrm{n}=3$; dry mouth, $\mathrm{n}=1$ ), nervous system disorders (headache, $\mathrm{n}=3$; dizziness, $\mathrm{n}=1)$, elevated blood pressure $(\mathrm{n}=1)$, rhinorrhea $(\mathrm{n}=1)$, expectoration difficulties $(\mathrm{n}=1)$, worsening vision $(\mathrm{n}=1)$, and noise in ears upon awakening $(\mathrm{n}=1)$ were revealed in Rengalin group.

Two serious AEs (SAEs) were registered in Rengalin group: type A flu $(\mathrm{n}=1)$ and COPD exacerbation $(\mathrm{n}=1)$. SAEs were not related to the study drug, the patients received adequate treatment, and the outcomes were recovery in the 1st case and improvement in the 2 nd one. One SAE was in Placebo group (myocardial infarction with lethal outcome).

In Rengalin group 14 (87.5\%) of AEs were mild, 1 $(6.25 \%)$ was moderate and $1(6.25 \%)$ was severe. AEs in Placebo group were mild $(\mathrm{n}=11(91.7 \%))$ and severe $(\mathrm{n}=1$ $(8.3 \%))$. A cause and effect relationship between the AEs and Rengalin, according to the physician-investigators, was not found in $81.25 \%(\mathrm{n}=13)$ of cases, was doubtful in $6.25 \%(\mathrm{n}=1)$ and was possible in $12.5 \%(\mathrm{n}=2)$. No AEs were registered with causal relationship to the study drug. Frequency distribution of the severity of AEs $(p=1.00)$ and significance of the cause-and-effect relationship to the drug $(p=1.00)$ did not differ in both groups.

During the study, there were no cases of Rengalin interaction with COPD maintenance medication (anticholinergics, beta-2 adrenergic agonists both short- and longacting, ICS), as well as the drugs used for concomitant therapy, including angiotensin receptor antagonists, calcium channel blockers, beta-adrenergic blockers, diuretics, imidazoline receptor agonists, statins, antiaggregants, oral hypoglycemic drugs, nitrates and drugs with nitrate-like properties, alpha-adrenergic blockers, neuroprotective drugs, nootropics, combined oral contraceptives.

Thus, the treatment was well tolerated by the patients and had a high compliance rate.

\section{Discussion}

This study demonstrated that the addition of Rengalin to the maintenance therapy of COPD leads to a clinically significant decrease in cough severity. The percentage of patients with a lower total cough score was statistically significantly higher in Rengalin group compared to Placebo group.

The placebo effect in cough therapy is common. In the review by Ron Eccles (2020), the perceived placebo 
Table 2 Cough Severity and CAT Scores

\begin{tabular}{|c|c|c|c|}
\hline \multirow[t]{2}{*}{ Parameter } & \multicolumn{2}{|c|}{ Group } & \multirow[t]{2}{*}{ Statistics } \\
\hline & Rengalin & Placebo & \\
\hline All Included Patients & $N=|2|$ & $N=117$ & \\
\hline Cough severity, Mean \pm SD (score) & $4.2 \pm 1.4$ & $4.1 \pm 1.4$ & $Z=0.49 ; p=0.63$ \\
\hline CAT, Mean \pm SD (score) & $19.9 \pm 6.6$ & $20.2 \pm 6.6$ & $Z=0.36 ; p=0.72$ \\
\hline CAT: $0-10$ score, number of patients, $n$ (\%) & II (9.1) & $8(6.8)$ & $\mathrm{P}=0.87$ \\
\hline CAT: II-20 score, number of patients, $n$ (\%) & $53(43.8)$ & $51(43.6)$ & \\
\hline CAT: $21-30$ score, number of patients, $n$ (\%) & $51(42.1)$ & $50(42.7)$ & \\
\hline CAT: $31-40$ score, number of patients, $n$ (\%) & $6(5.0)$ & $8(6.8)$ & \\
\hline ITT Analysis & $N=116$ & $N=113$ & Statistics \\
\hline Cough severity, Mean $\pm S D$ (score) & $4.2 \pm 1.4$ & $4.1 \pm 1.4$ & $Z=0.23 ; p=0.82$ \\
\hline CAT, Mean \pm SD (score) & $19.9 \pm 6.8$ & $20.3 \pm 6.6$ & $Z=0.43 ; p=0.67$ \\
\hline CAT: $0-10$ score, number of patients, $n$ (\%) & II (9.5) & $8(7.1)$ & $\mathrm{p}=0.87$ \\
\hline CAT: II-20 score, number of patients, $n$ (\%) & $50(43.1)$ & $49(43.4)$ & \\
\hline CAT: $21-30$ score, number of patients, $n$ (\%) & $49(42.2)$ & $48(42.5)$ & \\
\hline CAT: $31-40$ score, number of patients, $n$ (\%) & $6(5.2)$ & $8(7.1)$ & \\
\hline PP Analysis & $N=112$ & $N=110$ & Statistics \\
\hline Cough severity, Mean $\pm S D$ (score) & $4.2 \pm 1.4$ & $4.1 \pm 1.4$ & $Z=0.11 ; p=0.10$ \\
\hline CAT, Mean \pm SD (score) & $19.8 \pm 6.6$ & $20.3 \pm 6.7$ & $Z=0.50 ; p=0.61$ \\
\hline CAT: $0-10$ score, number of patients, $n$ (\%) & $10(8.9)$ & $8(7.3)$ & $\mathrm{p}=0.69$ \\
\hline CAT: II-20 score, number of patients, $n$ (\%) & $49(43.8)$ & $47(42.7)$ & \\
\hline CAT: $21-30$ score, number of patients, $n$ (\%) & $49(43.8)$ & $47(42.7)$ & \\
\hline CAT: $31-40$ score, number of patients, $n$ (\%) & $4(3.5)$ & $8(7.3)$ & \\
\hline
\end{tabular}

Notes: Analysis of the mean values was performed with Wilcoxon criterion. For subgroups comparison according to the number of patients Fisher's criterion was used.

response in patients with acute cough has been shown to be up to $85 \%$ in some clinical trials. ${ }^{15}$ In our study, the placebo effect was also significant (72.6 [72.7]\% of patients had clinically significant improvement in cough). However, the percentage of patients who responded to treatment was more significant in Rengalin group than in Placebo group.

One of the therapeutic goal of the cough treatment is a quality of life improvement. In our study, we showed Rengalin add-on therapy significantly reduced the impact of COPD on patient QoL. This was proven by a decrease of the CAT questionnaire total score. Statistically significant differences were found according to the PP analysis, ie, in patients who received full course of Rengalin treatment in combination with maintenance therapy. The results of the ITT analysis, that included all randomized patients who started but did not complete treatment according to the protocol, did not reach statistical significance.

Smith and Woodcock in the review (2006) noticed that cough is independently associated with disability in
COPD. Improved outcome measures of cough, a better understanding of cough in the natural history of COPD, and its importance to patients are needed. ${ }^{16}$ Pierre-Regis Burgel, editor of the European Respiratory Journal, in 2012 suggested a hypothesis that chronic cough and sputum production can be a clinical COPD phenotype. ${ }^{17}$ The nationwide multicenter cohort study (KOCOSS) has shown that a chronic cough is associated with lower FEV1 and diffusing capacity of the lungs for carbon monoxide, more severe dyspnea, worse QoL, and a chronic cough is an independent risk factor for future acute exacerbations of COPD. ${ }^{18}$ Peter MA Calverley in review (2013) states "the assessment and treatment of cough should have a more prominent place in the clinical management of COPD". 19 Thus, the treatment of cough is a challenge for pulmonologist and other doctors curing patients with COPD.

Prolonged cough in COPD is caused by mucus hypersecretion associated with mucosal metaplasia and an increased number of goblet cells in response to the irritation caused by tobacco smoke. Sputum 


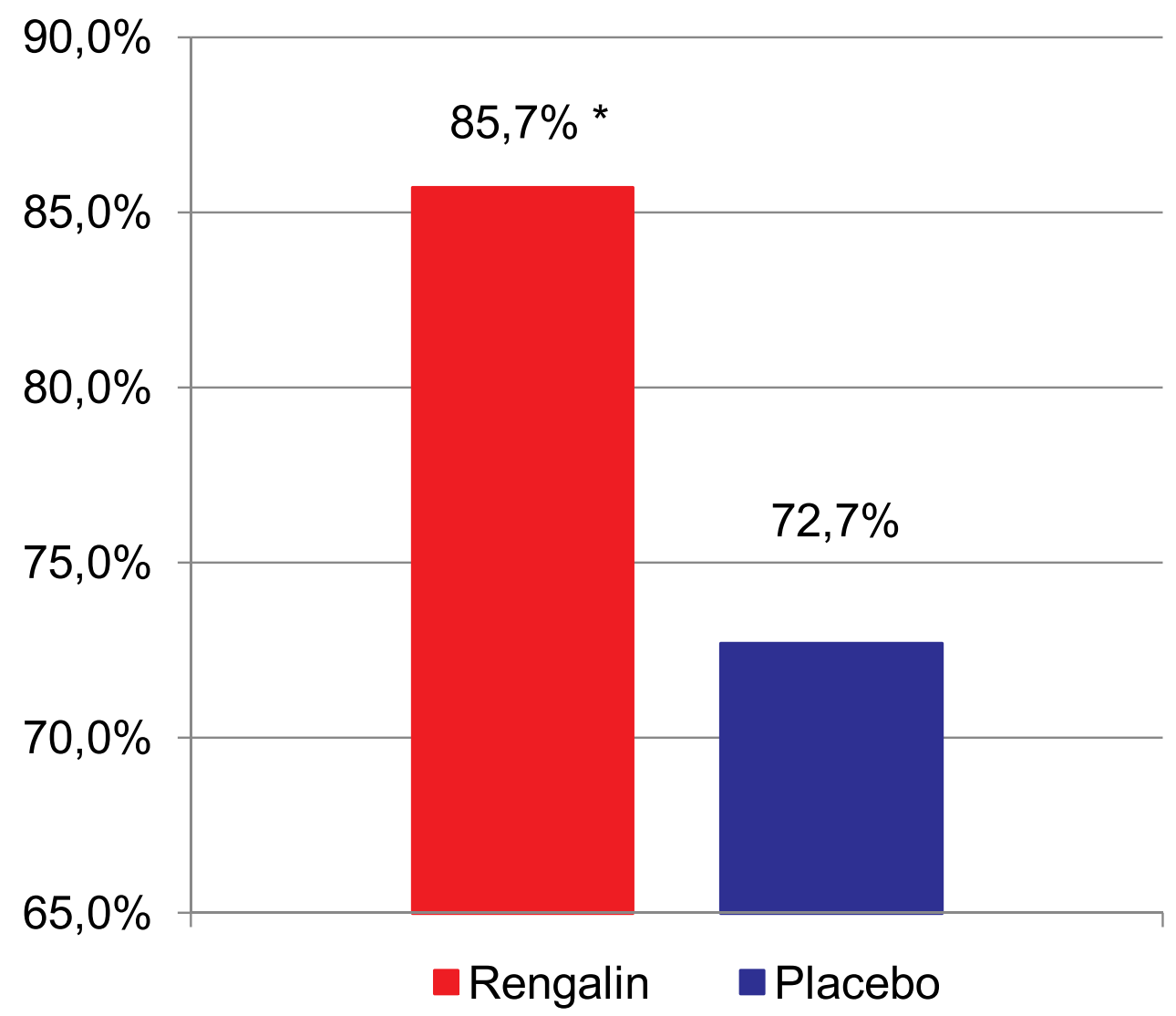

Figure 2 Percentage of patients responsive to treatment. PP analysis data. ${ }^{*} p=0.016$.

hypersecretion and changes in its rheological characteristics lead to a viscosity increase, bronchial secretion slowdown and dyskinesia of the ciliated epithelium. These changes contribute to microbial colonization, aggravation of the inflammation and bronchial obstruction, as well as the formation of oxidative stress. ${ }^{1}$ One of the main tasks of COPD therapy is to influence these pathogenetic processes. Mucolytic drugs, primarily with antioxidant properties, are used to control cough in COPD. In double-blind placebo-controlled studies, erdosteine reduced the frequency and duration of exacerbations. ${ }^{20,21}$ A systematic review of the results of 34 studies that included 9367 participants with chronic bronchitis or COPD demonstrated that mucolytic therapy can reduce the number of exacerbations and have a positive impact on the patients' QoL. Such symptomatic therapy can be a great addition to maintenance therapy for patients with frequent exacerbations and poor QoL. ${ }^{22}$

However, symptoms of mucus hypersecretion are not found in all of the patients with cough in COPD.
Currently, it remains relevant to identify the correlation between COPD and cough hypersensitivity syndrome (an increased response of afferent nerve endings to chemical or mechanical stimulation). The role of the hypersensitive cough response in the pathogenesis of the cough reflex in patients with COPD should not be excluded. $^{23}$ In the study of patients with COPD, an enhanced cough response to capsaicin was ound. ${ }^{24}$ Thus, it is possible to influence the sensitivity of cough receptors in order to relieve cough severity.

The therapeutic effects of Rengalin are due to its modifying effect on opioid, histamine and bradykinin ligandreceptor interactions. Rengalin decreases the excitability of the cough center, and also decreases the pain signals from periphery via inhibiting release of such tissue and plasma substances as histamine, bradykinin and prostaglandins. ${ }^{13}$

However, we faced large data variability across the number of secondary endpoints. Despite a significant decrease in the average total cough symptom score in 
Table 3 Total CAT Score

\begin{tabular}{|c|c|c|c|c|}
\hline & \multicolumn{2}{|c|}{ ITT Analysis } & \multicolumn{2}{|c|}{ PP Analysis } \\
\hline & Rengalin $(N=116)$ & Placebo $(N=|| 3)$ & Rengalin (N = I|2) & Placebo $(\mathbf{N}=1 \mid 0)$ \\
\hline \multicolumn{5}{|c|}{ Total score at baseline } \\
\hline Mean \pm SD & $19.9 \pm 6.8$ & $20.3 \pm 6.6$ & $19.8 \pm 6.6$ & $20.3 \pm 6.7$ \\
\hline Median & 20.0 & 20.0 & 20.0 & 20.5 \\
\hline QI-Q3 & $14.5-25.0$ & $16.0-24.0$ & $14.5-25.0$ & $16.0-24.0$ \\
\hline$[95 \% \mathrm{Cl}]$ & $\mid 8.6-21.1$ & $19.1-21.6$ & $18.5-21.0$ & $19.1-21.6$ \\
\hline \multicolumn{5}{|c|}{ Total score after 4 weeks of treatment } \\
\hline Mean $\pm S D$ & $16.6 \pm 6.9$ & $17.8 \pm 6.8$ & $16.2 \pm 6.6$ & $17.8 \pm 6.9$ \\
\hline Median & 16.0 & 18.0 & 16.0 & 18.0 \\
\hline QI-Q3 & $11.0-22.0$ & $13.0-22.0$ & $11.0-21.0$ & $13.0-22.0$ \\
\hline$[95 \% \mathrm{Cl}]$ & $15.3-17.8$ & $16.5-19.1$ & $15.0-17.4$ & $16.5-19.1$ \\
\hline \multicolumn{5}{|c|}{$\Delta$ (between baseline and after 4 weeks) } \\
\hline Mean \pm SD & $3.3 \pm 4.2$ & $2.5 \pm 4.1$ & $3.6 \pm 3.9$ & $2.5 \pm 4.2$ \\
\hline Median & 3.0 & 2.5 & 3.0 & 2.5 \\
\hline QI-Q3 & $1.0-5.0$ & $0.0-5.0$ & $1.0-5.5$ & $0.0-5.0$ \\
\hline$[95 \% \mathrm{Cl}]$ & $2.5-4.1$ & I.8-3.3 & $2.8-4.3$ & I.7-3.3 \\
\hline \multicolumn{5}{|c|}{$\Delta$ (between Rengalin and Placebo groups) } \\
\hline Mean \pm SD & \multicolumn{2}{|c|}{$0.79 \pm 4.16$} & \multicolumn{2}{|c|}{$1.04 \pm 4.02$} \\
\hline$[95 \% \mathrm{Cl}]$ & \multicolumn{2}{|c|}{$-0.29-1.87$} & \multicolumn{2}{|c|}{$-0.02-2.11$} \\
\hline \multirow[t]{2}{*}{ Statistics } & \multirow{2}{*}{\multicolumn{2}{|c|}{$\begin{array}{c}Z=1.71 \\
P=0.0870\end{array}$}} & \multicolumn{2}{|c|}{$Z=2.04$} \\
\hline & & & \multicolumn{2}{|c|}{$P=0.0416$} \\
\hline
\end{tabular}

Notes: Analysis was performed using Wilcoxon criterion; the result of the null test with Shapiro Wilk criterion confirming abnormal data distribution: for ITT Rengalin sample $p=0.0006$, Placebo $-p=0.000$ I; for PP Rengalin sample $-p=0.0080$, Placebo $-p=0.000$ I. Mean $\pm S D-$ mean value and its standard deviation. $C l-c o n f i d e n c e$ interval. The threshold of the first and third quartiles are shown (QI-Q3) due to the lack of normal distribution of parameters.

Rengalin group, there were no significant differences between the groups. In more than $40 \%$ of patients taking Rengalin along with maintenance therapy, the cough severity decreased by 2 times or more but, similarly to the previous endpoint, the differences were not statistically significant. Probably, it was due to the wide data range of the decrease in the total cough symptom score, for which the standard deviation was several times higher than the delta value.

There was no significant effect of the combined therapy on the incidence of COPD exacerbations.

The results obtained during the study show the safety of using Rengalin in patients with COPD. The low rate of AEs in Rengalin group, which did not differ significantly from that of Placebo group, confirms a favorable profile for the drug's safety.

Thus, the results of this study confirm the need for cough management in patients with COPD. The effect of the combination drug on various parts of the cough reflex pathogenesis during the 4 weeks decreased cough severity, and QoL associated with it, for most patients, which makes it possible to achieve therapeutic goals for patients with COPD.

\section{Study Limitations}

In the study, the drug was used in addition to the maintenance therapy for COPD, which included anticholiner-

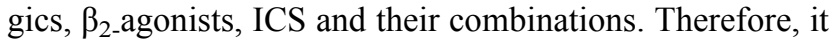
was not possible to evaluate the effect of monotherapy with Rengalin. The study did not include patients with COPD exacerbation and disease progression in the past 6 months.

\section{Conclusion}

The results of the study showed the efficacy and safety of Rengalin in patients with stable COPD and persistent cough despite stable doses of maintenance therapy according to GOLD recommendations. A response to Rengalin add-on to the maintenance treatment for 4 weeks was in most patients, and it significantly decreased the extent of COPD's impact on patient's QoL. Patients with COPD 


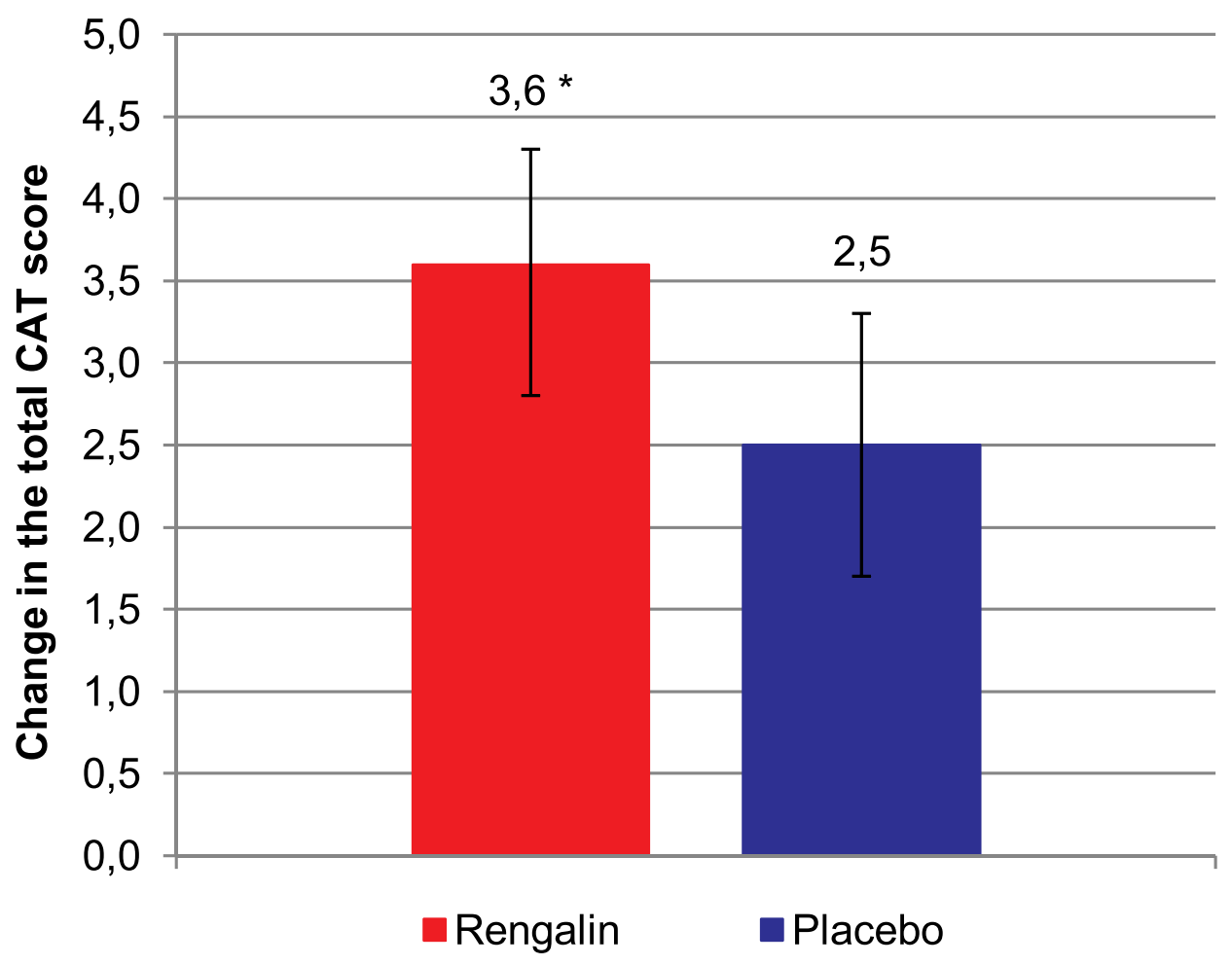

Figure 3 The change of the total CAT score after 4 weeks of treatment. PP analysis data. ${ }^{*} \mathrm{p}=0.0416$.

tolerated Rengalin well and demonstrated high level of therapy compliance.

\section{Abbreviations}

AEs, adverse events; CAT, COPD assessment test; COPD, chronic obstructive pulmonary disease; CSS, cough severity scale; FAS, full analysis set; $\mathrm{FEV}_{1}$, forced expiration volume in 1 second; FVC, forced vital capacity; GCP, good clinical practice; GOLD, Global Initiative for Chronic Obstructive Lung Disease; ICS, inhaled corticosteroids; ITT, intention-to-treat; PP, per protocol; SAE, serious adverse event; SAS-9.4, statistical analysis system-9.4.

\section{Data Sharing Statement}

The data used to support the findings of this study are included within the article. No additional data are available.

\section{Funding}

This study was funded by OOO NPF MATERIA MEDICA HOLDING. Rengalin is a preparation manufactured and marketed by OOO NPF MATERIA MEDICA HOLDING.
OOO NPF MATERIA MEDICA HOLDING holds the patent on Rengalin.

\section{Disclosure}

Avdeev S.N., MD, PhD, professor, Vizel' A.A., MD, PhD, professor, Abrosimov V.N., MD, $\mathrm{PhD}$, professor, Ignatova G.L., MD, PhD, professor, Khamitov R.F., MD, PhD, professor, Mikhaylusova M.P., MD, PhD, Shapovalova Yu.S., MD, PhD, Pavlysh E.F., MD, PhD, Trofimov V.I., $\mathrm{MD}, \mathrm{PhD}$, professor, Emel'yanov A.V., MD, PhD, professor, Martynenko T.I., MD, PhD, professor, Martynenko V. A., MD, PhD, Kostina N.E., MD, PhD, Chizhov D.A., MD, Chizhova O.Yu., MD, PhD, professor, Kuzubova N. A., MD, PhD, Makova E.V., MD, PhD, and Makarova E. $\mathrm{V}$., $\mathrm{MD}, \mathrm{PhD}$ received an investigator grant from Materia Medical Holding to conduct the clinical trial of Rengalin mentioned in this article. The authors report no other conflicts of interest in this work.

\section{References}

1. Global Initiative for Chronic Obstructive Lung Disease. Global strategy for the diagnosis, management and prevention of COPD; 2020 [Internet]. Available from: https://goldcopd.org/gold-reports/. Accessed December 10, 2019. 
2. Miravitlles M, Ribera A. Understanding the impact of symptoms on the burden of COPD. Respir Res. 2017;18(1):67. doi:10.1186/ s12931-017-0548-3

3. Jones PW, Brusselle G, Dal Negro RW, et al. Patient-centred assessment of COPD in primary care: experience from a cross-sectional study of health-related quality of life in Europe. Prim Care Respir J. 2012;21(3):329-336. doi:10.4104/pcrj.2012.00065

4. Global Initiative for Chronic Obstructive Lung Disease. World lung day; September 25, 2019. Available from: https://goldcopd.org/ world-lung-day-2019-respiratory-groups-unite-to-call-for-healthylungs-for-all/. Accessed April 16, 2021.

5. Wacker ME, Kitzing K, Jörres RA, et al. The contribution of symptoms and comorbidities to the economic impact of COPD: an analysis of the German COSYCONET cohort. Int J Chronic Obstr Pulm Dis. 2017;12:3437. doi:10.2147/COPD.S141852

6. Miravitlles M, Worth H, Soler Cataluna JJ, et al. Observational study to characterise 24-hour COPD symptoms and their relationship with patient-reported outcomes: results from the ASSESS Study. Respir Res. 2014;15(1):122. doi:10.1186/s12931-014-0122-1

7. Chuchalin AG, Abrosimov VN, Cough M. GEOTAR-media; 2016:160. (in Russ).

8. Epstein O. The spatial homeostasis hypothesis. Symmetry. 2018;10 (4):103. doi:10.3390/sym 10040103

9. Tarasov SA, Gorbunov EA, Don ES, et al. Insights into the mechanism of action of highly diluted biologics. J Immunol. 2020;205(issue 5):1345-1354. doi:10.4049/jimmunol.2000098

10. Rafalsky V, Averyanov A, Bart B, et al. Efficacy and safety of Ergoferon versus oseltamivir in adult outpatients with seasonal influenza virus infection: a multicenter, open-label, randomized trial. Int J Infect Dis. 2016;51:47-55. doi:10.1016/j.ijid.2016.09.002

11. Mkrtumyan A, Romantsova T, Vorobiev S, et al. Efficacy and safety of Subetta add-on therapy in type 1 diabetes mellitus: the results of a multicenter, double-blind, placebo-controlled, randomized clinical trial. Diabetes Res Clin Pract. 2018;142:1-9. doi:10.1016/j. diabres.2018.04.044

12. Pushkar D, Vinarov A, Spivak L, et al. Efficacy and safety of Afalaza in men with symptomatic benign prostatic hyperplasia at risk of progression: a multicenter, double-blind, placebo-controlled, randomized clinical trial. Cent European J Urol. 2018;71(4):427-435. doi:10.5173/ceju.2018.1803

13. Instruction for medical use, Rengalin; 2020. Available from: https:// grls.rosminzdrav.ru/Grls_View_v2.aspx?routingGuid=f60f62 6 18b2-43f2-83e4-1c97742f0eba\&t=. Accessed April 20, 2020.
14. Hsu JY, Stone RA, Logan-Sinclair RB, Worsdell M, Busst CM, Chung KF. Coughing frequency in patients with persistent cough: assessment using a 24 hour ambulatory recorder. Eur Respir J. 1994;7(7):1246-1253. doi:10.1183/09031936.94.07071246

15. Eccles R. The powerful placebo effect in cough: relevance to treatment and clinical trials. Lung. 2020;198(1):13-21. doi:10.1007/ s00408-019-00305-5

16. Smith J, Woodcock A. Cough and its importance in COPD. Int J Chron Obstruct Pulmon Dis. 2006;1(3):305-314. doi:10.2147/ copd.2006.1.3.305

17. Burgel P-R. Chronic cough and sputum production: a clinical COPD phenotype? Eur Respir J. 2012;40(1):4-6. doi:10.1183/090319 36.00022412

18. Koo HK, Park SW, Park JW, et al. Chronic cough as a novel phenotype of chronic obstructive pulmonary disease. Int J Chron Obstruct Pulmon Dis. 2018;13:1793-1801. doi:10.2147/COPD.S153821

19. Calverley PM. Calverley: cough in chronic obstructive pulmonary disease: is it important and what are the effects of treatment? Cough. 2013;9(1):17. doi:10.1186/1745-9974-9-17

20. Dal Negro RW, Wedzicha JA, Iversen M, et al. Effect of erdosteine on the rate and duration of COPD exacerbations: the RESTORE Study. Eur Respir J. 2017;50(4):1700711. doi:10.1183/13993003. 00711-2017

21. Rogliani P, Matera MG, Page C, Puxeddu E, Cazzola M, Calzetta L. Efficacy and safety profile of mucolytic/antioxidant agents in chronic obstructive pulmonary disease: a comparative analysis across erdosteine, carbocysteine, and N-acetylcysteine. Respir Res. 2019;20 (1):104. doi:10.1186/s12931-019-1078-y

22. Poole P, Chong J, Cates CJ. CD001287 Cochrane database of systematic reviews. Mucolytic agents versus placebo for chronic bronchitis or chronic obstructive pulmonary disease. Cochrane Database Syst Rev. 2019. doi:10.1002/14651858.CD001287

23. Chikina SY. Cough hypersensitivity syndrome. Pulmonology. 2015;25(2):224-228. (in Russ). doi:10.18093/0869-0189-2015-252-224-228

24. Belvisi MG, Birrell MA, Khalid S, et al. Neurophenotypes in airway diseases. Insights from translational cough studies. Am J Respir Crit Care Med. 2016;193(12):1364-1372. doi:10.1164/rccm.201508$1602 \mathrm{OC}$

\section{Publish your work in this journal}

The International Journal of COPD is an international, peer-reviewed journal of therapeutics and pharmacology focusing on concise rapid reporting of clinical studies and reviews in COPD. Special focus is given to the pathophysiological processes underlying the disease, intervention programs, patient focused education, and self management protocols. This journal is indexed on PubMed Central, MedLine and CAS. The manuscript management system is completely online and includes a very quick and fair peer-review system, which is all easy to use. Visit http://www.dovepress.com/testimonials.php to read real quotes from published authors. 